\title{
Treatment Outcomes and Patterns of Failure in Elderly Patients with Cervical Cancer Treated with Definitive Radiotherapy
}

\author{
(1) Gautam SARMA, (D) Luri BORAH, (D) Jyotiman NATH, Mouchumee BHATTACHARYYA, \\ (D) Partha Pratim MEDHI, (D) Apurba Kumar KALITA
}

Department of Radiation Oncology, Dr. Bhubaneswar Borooah Cancer Institute, Guwahati, Assam-India

\begin{abstract}
OBJECTIVE
The incidence of cervical cancer among older women is increasing. The treatment outcome in these patients is affected byvarious patient and tumor-related factors. In this study, we retrospectively investigated the survival outcomes, treatment-related toxicity, and patterns of failures for elderly patients $(\geq 75$ years old) with cervical cancer treated with definitive radiotherapy.
\end{abstract}

\section{METHODS}

Twenty-three patient's fulfilling inclusion and exclusion criteria were analyzed. The survival was studied using the Kaplan-Meir method, and its relation with different clinicopathologic parameters was compared.

\section{RESULTS}

After a median follow-up time of 46 months (range 3-93), the overall survival for the entire cohort of patients at 5 years and 7 years were $54.9 \%$ and $43.9 \%$, respectively, and the disease-free survival at 3 years and 5 years were $66.3 \%$ and $45.9 \%$ respectively. Patients receiving total radiation dose (EqD2) more than $80 \mathrm{~Gy}$ achieved statistically significant improved survival than those receiving lower doses $(\mathrm{p}=0.04)$. Grade III acute toxicity was experienced by 2 patients $(8.7 \%)$ with diarrhea and one patient $(4.3 \%)$ with dermatitis, but no grade IV acute toxicity was recorded. Two patients (8.7\%) developed rectal bleeding as late toxicity. At the end of follow-up, 11 patients (47.8\%) experienced a relapse. Distant metastasis to the lung was the most common type of failure.

\section{CONCLUSION}

Definitive radiotherapy is safe and well-tolerated by elderly patients with cervix cancer with an acceptable degree of toxicities.

Keywords: Cancer; cervix; chemotherapy; elderly; radiotherapy.

Copyright $\odot$ 2021, Turkish Society for Radiation Oncology

\section{Introduction}

Cervical cancer is the fourth most common malignancy in women and remains one of the leading causes of cancer-related morbidity worldwide. In India, it is the second most common cancer in women.[1,2] The incidence and mortality due to cervical cancer is declining in developed countries. This is primarily due 
to the increase of knowledge that persistent human papillomavirus (HPV) infection is the leading cause of cervical cancer, resulting in the development of prophylactic vaccines. However, it is still a significant health problem in developing countries due to the lack of routine screening and introduction of vaccination programs. $[3,4]$

Cervical cancer demonstrates a bimodal age distribution, with peaks between 30 to 39 years and 60 to 69 years. Data from various hospital-based cancer registries (HBCR) of India reports the mean age of presentation ranging between 50 and 56.7 years. Patients above 65 years of age account for around $15 \%$ of these HBCRs. With the increase in life expectancy of the population, the incidence of cervical cancer among elderly women is increasing. [5,6] Elderly patients are heterogeneous to comorbidities, performance status, access to healthcare and motivation towards screening programs, etc. These factors contribute to the delayed diagnosis and compromised treatment of this age group?. Moreover, various reports have demonstrated that elderly women often present with more advanced staged disease and receive less aggressive treatment. $[7,8]$

There are conflicting reports on the impact of age on treatment outcome in cervical cancer. Many studies have reported age to be a prognostic factor in cervix cancer.[9-12] Some studies have shown a similar prognosis of cervical cancer in old and young women, while few demonstrated that younger age is an unfavorable prognostic factor. $[13,14]$ However, there are kinds of literature which reported younger patients might have improved outcome and old age is a poor prognostic factor.[15-17]

In this study, we retrospectively analyzed the survival outcomes, treatment-related toxicity, and patterns of failures for elderly women ( $\geq 75$ years) with cervical cancer treated with definitive radiotherapy (RT) with or without concurrent chemotherapy (CCRT).

\section{Materials and Methods}

\section{Patient Selection and Assessment}

Cervical cancer patients treated between 2011 and 2015 in our institute were retrospectively reviewed. The inclusion criteria were as follows: age 75 years or more, histologically proven carcinoma of the cervix, patients treated with definitive radiotherapy, no prior history of surgery, chemotherapy or radiation for carcinoma cervix, and no evidence of distant metastasis. Patients treated with palliative radiotherapy were ex- cluded from the study. Twenty-three patients $(n=23)$ fulfilling inclusion and exclusion criteria were included in the analysis.

The patients were staged according to the International Federation of Gynaecology and Obstetrics (FIGO-2009) staging system.[18] The findings of clinical examination notes, chest roentgenography, intravenous pyelography, cystoscopy, and proctoscopy were used for staging. Patients' baseline Eastern Cooperative Oncology Group (ECOG) performance status and comorbidities were also recorded.

\section{Treatment}

All the patients received Radiotherapy with curative intent. The patients received external beam radiotherapy (EBRT) with a conventional technique. Patients were treated in a supine position using a thermoplastic pelvic mould for immobilization. X-Ray simulation was done in Simulix Evolution (Nucletron) conventional simulator for treatment planning. EBRT was delivered using the four-field box technique with $6 \mathrm{MV}$ photons in Elekta Precise digital linear accelerator (LA) and Siemens Primus LA. EBRT dose ranged between 46-50 Gy in 2Gy daily fractions. Three patients received concurrent chemotherapy with weekly inj Carboplatin AUC 2 for 5 cycles.

EBRT was followed by high dose rate (HDR) intracavitary brachytherapy (ICBT) in Microselectron HDR (Nucletron, The Netherlands) using a 192-Iridium remote afterloading unit. Two patients did not receive brachytherapy as they defaulted after EBRT and one patient received EBRT boost as brachytherapy could not be performed because of the stenosed vagina. Treatment planning for HDR-ICBT was performed using PLATO Brachytherapy Planning System version 3.2 (Nucletron, The Netherlands). Evaluation of the rectal and bladder dose was performed according to ICRU Report 38.[19] The dose of brachytherapy was either $700 \mathrm{cGy}$ or $750 \mathrm{cGy}$ to point $\mathrm{A}$ for 2 to 4 fractions.

\section{Follow-up}

After completion of treatment, the patients were followed up by both gynecological and radiation oncologists. A gynecological examination was performed in each follow-up. Radiological investigations like computed tomography (CT) or magnetic resonance imaging (MRI) were performed as and when necessary.

Both acute and late treatment-related toxicities were evaluated using medical records and CTC-AE 
version 4.0. Toxicities occurring within 90 days of the start of treatment were defined as acute, and those that occurred after 90 days persisted beyond 90 days of start of treatment were coined as late.

\section{Statistical Analysis}

Baseline variables were depicted as numbers (Percentage). Kaplan Meir's method was used to evaluate the survival rate, and the log-rank test was used to compare the survival among groups, and the t-test was used to compare two means. $\mathrm{P}<0.05$ is considered as statistically significant at $95 \%$ confidence interval. All data were analyzed using IBM SPSS Statistics for Windows, version 21 (IBM Corp., Armonk, N.Y., USA).

\section{Results}

\section{Patient Characteristics and Treatment}

During the period 2011 to 2015, a total of 23 patients were eligible for the analysis. The baseline patient characteristics are depicted in Table 1. The median age was 77 years (range 75-85). The majority of the patients (19 patients, $82.6 \%$ ) had squamous cell carcinoma. Two patients (8.7\%) had adenocarcinoma; one patient

\begin{tabular}{|c|c|c|}
\hline $\begin{array}{l}\text { Patient } \\
\text { characteristics }\end{array}$ & $\begin{array}{l}\text { nber of patients } \\
\text { (Total } n=23 \text { ) }\end{array}$ & Percentage \\
\hline \multicolumn{3}{|l|}{ Age } \\
\hline Median (Range) & $77(75-85)$ & \\
\hline $75-80$ years & 16 & $69.6 \%$ \\
\hline$>80$ years & 7 & $30.4 \%$ \\
\hline \multicolumn{3}{|l|}{ PS (ECOG) } \\
\hline 0 to 1 & 14 & $60.9 \%$ \\
\hline 2 to 3 & 9 & $39.1 \%$ \\
\hline \multicolumn{3}{|l|}{ Stage(FIGO) } \\
\hline IB2 & 2 & $8.7 \%$ \\
\hline IIB & 10 & $43.5 \%$ \\
\hline IIIB & 8 & $34.8 \%$ \\
\hline IVA & 3 & $13.0 \%$ \\
\hline \multicolumn{3}{|l|}{ Histology } \\
\hline Squamous cell carcinoma & 19 & $82.6 \%$ \\
\hline Adenocarcinoma & 2 & $8.7 \%$ \\
\hline Adeno Squamous & 1 & $4.3 \%$ \\
\hline Small cell & 1 & $4.3 \%$ \\
\hline \multicolumn{3}{|l|}{ Medical co-morbidity } \\
\hline Yes & 12 & $52.2 \%$ \\
\hline No & 11 & $47.8 \%$ \\
\hline
\end{tabular}

(4.3\%) had adenosquamous and one patient (4.3\%) had small cell carcinoma histology. The FIGO stage of the patients ranged from IB2 to IVA. Stage IIB was most common (10 patients; $43.5 \%)$ followed by IIIB (8 patients; $34.8 \%$ ), IVA (3 patients; 13\%) and IB292 patients; $8.7 \%)$ respectively. Twelve patients (52.2\%) had medical comorbidities like diabetes or hypertension or both.

The patients received EBRT by a conventional treatment planning to a dose ranging from 46 to $50 \mathrm{~Gy}$ in $2 \mathrm{~Gy}$ daily fractions with the four-field box technique. Twenty patients $(86.9 \%)$ received HDR-ICBT. The brachytherapy dose was either 7 Gy or 7.5 Gy per fraction for 2-4 fractions. One patient received an external beam boost of $14 \mathrm{~Gy}$ in 7 fractions as brachytherapy could not be planned due to stenosed vagina and two patients $(8.7 \%)$ defaulted and did not receive brachytherapy. Total brachytherapy dose (EqD2) was more than $30 \mathrm{~Gy}$ in 10 patients (43.5\%) and less than $30 \mathrm{~Gy}$ in another 10 patients (43.5\%). The overall duration of radiotherapy ranged from 42 to 70 days, with a median of 55 days. Fourteen patients (60.9\%) completed their entire course of treatment in less than 8 weeks. Only three patients (13\%) received concurrent chemotherapy with weekly inj Carboplatin AUC 2 for 5 cycles.

\section{Survival}

The median follow-up time was 46 months (range 3-93). At the end, nine patients (39.1\%) were alive. The overall survival (OS) for the entire cohort of patients at 5 years and 7 years was $54.9 \%$ and $43.9 \%$ respectively and the disease-free survival (DFS) at 3 years and 5 years were $66.3 \%$ and $45.9 \%$, respectively (Fig. 1).

The univariate analysis of various patient and treatment parameters influencing OS and DFS are shown in Table 2. The OS at 5 years and 7 years for the patients with pre-treatment ECOG score 0 - 1 are superior to those with score 2-3, but the statistical difference only reached borderline significance $(p=0.06)$. The patients of stage IB2-IIB had superior 5-year OS and DFS $(66.7 \%$ and $46.3 \%)$ than of stage IIIB-IVA $(41.6 \%$ and $44.4 \%) ; \mathrm{p}=0.12$ and 0.54 respectively. The patients of squamous cell carcinoma histology had statistically significant improved OS and DFS (Fig. 2) ( $\mathrm{p}=0.009$ and $\mathrm{p}<0.001$ respectively).

The median total radiation dose (EqD2, 2 Gy equivalent dose) including, EBRT and ICBT of the patients was $79.75 \mathrm{~Gy}$ (range 50-85.67). Nine patients (39.1\%) received more than $80 \mathrm{~Gy}$. The OS at 5 years of the pa- 

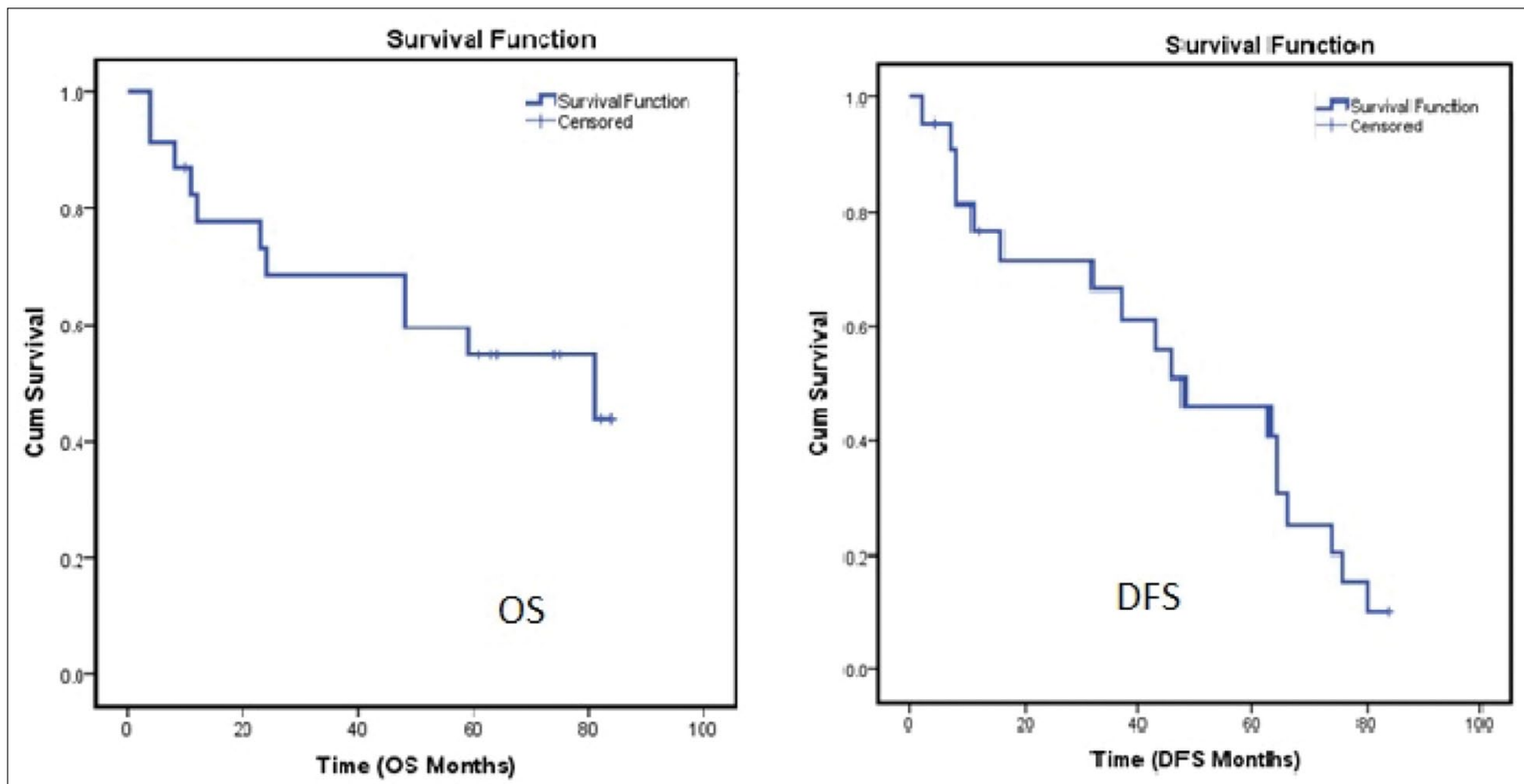

Fig. 1. Overall survival and disease-specific survival (OS and DSS) rates for all patients using the Kaplan-Meier method.

Table 2 Comparison of survival among various patient and treatment-related factors

\begin{tabular}{|c|c|c|c|c|c|c|c|}
\hline \multirow[t]{2}{*}{ Variable } & \multirow[t]{2}{*}{ No. of patients (\%) } & \multicolumn{3}{|c|}{ Overall survival (OS) } & \multicolumn{3}{|c|}{ Disease-free survival (DFS) } \\
\hline & & 5 Yrs (\%) & 7 Yrs (\%) & $\mathbf{p}$ & 3Yrs (\%) & 5 Yrs (\%) & $\mathbf{p}$ \\
\hline \multicolumn{8}{|l|}{ PS } \\
\hline 0 to 1 & $14(60.9 \%)$ & 69.2 & 51.9 & $0.06^{*}$ & 64.3 & 42.9 & 0.6 \\
\hline 2 to 3 & $9(39.1 \%)$ & 33.3 & 33.3 & & 71.4 & 53.6 & \\
\hline \multicolumn{8}{|l|}{ Stage } \\
\hline IB2-IIB & $12(52.2 \%)$ & 66.7 & 66.7 & 0.12 & 64.8 & 46.3 & 0.5 \\
\hline IIIB-IVA & $11(47.8 \%)$ & 41.6 & 27.7 & & 66.7 & 44.4 & \\
\hline \multicolumn{8}{|l|}{ Histopathology } \\
\hline SCC & $19(82.6 \%)$ & 63.2 & 50.5 & $0.009^{*}$ & 81.6 & 56.5 & $<0.001^{*}$ \\
\hline Others & $4(17.4 \%)$ & 0 & 0 & & 0 & 0 & \\
\hline \multicolumn{8}{|c|}{ Total ICRT dose (EqD2) } \\
\hline Less than 30Gy & $10(43.5 \%)$ & 40 & 40 & 0.2 & 46.7 & 23.3 & 0.1 \\
\hline 30 Gy or more & $10(43.5 \%)$ & 78.8 & 52.5 & & 80 & 60 & \\
\hline Not taken & $3(13.0 \%)$ & 33.3 & 33.3 & & 100 & 100 & \\
\hline \multicolumn{8}{|c|}{ Total radiation dose (EqD2) } \\
\hline Less than $80 \mathrm{~Gy}$ & $14(60.9 \%)$ & 35.7 & 35.7 & $0.04^{*}$ & 48.2 & 28.9 & 0.3 \\
\hline 80 Gy or more & $9(39.1 \%)$ & 87.5 & 58.3 & & 88.9 & 66.7 & \\
\hline \multicolumn{8}{|c|}{ Total treatment duration (Days) } \\
\hline 56 or less & $14(60.9 \%)$ & 62.3 & 62.3 & 0.2 & 76 & 59.1 & $0.03^{*}$ \\
\hline More than 56 & $9(39.1 \%)$ & 44 & 0 & & 53.3 & 26.7 & \\
\hline \multicolumn{8}{|c|}{ Concurrent chemotherapy } \\
\hline Yes & $3(13 \%)$ & 66.7 & 66.7 & 0.5 & 33 & 0 & $0.04^{*}$ \\
\hline No & $20(87 \%)$ & 53.1 & 42.5 & & 72 & 54 & \\
\hline
\end{tabular}

*Statistically significant. PS: Performance Score; SCC: Squamous Cell Carcinoma; ICRT: Intracacitary Radiotherapy. 
tients receiving more than $80 \mathrm{~Gy}$ was superior to those receiving lesser doses $(87.5 \%$ vs $35.5 \%$ respectively; $\mathrm{p}=0.04$ ) Figure 2. The patients completing the entire course of treatment, within 8 weeks had improved OS and DFS at 5 years $(62.3 \%$ and $59.1 \%$ respectively) in comparison to those taking longer treatment time ( $44 \%$ and $26.7 \%$ respectively); $\mathrm{p}=0.2$ and 0.03 respectively (Fig. 2). The three patients who received concurrent chemotherapy had improvement of OS at 5 years than the others $(66.7 \%$ vs $53.1 \%)$ but the difference is not statistically significant $(\mathrm{p}=0.5)$. However, no benefit was observed in terms of DFS in these patients receiving concurrent chemotherapy with Carboplatin.

\section{Treatment-Related Acute and Chronic Toxicities}

The acute and chronic treatment-related toxicities are shown in Table 3. Thirteen patients (56.2\%) experienced acute gastrointestinal toxicity. Grade III acute toxicity was experienced by two patients $(8.7 \%)$ with diarrhea and one patient (4.3\%) with dermatitis, but no grade IV acute toxicity was recorded. The patients experiencing grade II-III diarrhea were managed conservatively with intravenous fluid and anti-diarrheal agents. Ten patients (43.5\%) developed grade II dermatitis and only one patient (4.3\%) developed grade III dermatitis. Grade I and II anemia were recorded in
$8(34.8 \%)$ and $4(17.4 \%)$ patients respectively during treatment.

Two patients (8.7\%) developed late rectal bleeding due to proctitis for which they had to undergo argon plasma photocoagulation. Only one patient (4.3\%) within the entire cohort developed grade II lymphedema of the bilateral lower limbs. Eleven patients $(47.8 \%)$ developed varying grades of vaginal stricture including one patient $(4.3 \%)$ with grade III. One patient $(4.3 \%)$ developed grade II cystitis and presented with moderate haematuria.

\section{Patterns of Failure}

Failure was defined as either recurrence of disease or persistent disease following radiotherapy. The failure was classified as 1. Locoregional: a residual or recurrent disease at cervix or uterus and/or pelvic failures below L5-S1 level including nodal, parametrial, and vaginal; 2. Distant: systemic spread, supraclavicular, and/or inguinal spread; 3. PA nodes above L5-S1.

The patterns of failure are shown in Table 4. At the end of follow-up, 11 patients $(47.8 \%)$ experienced a relapse. The details of various patterns of failure are shown in Table 4. Four patients (17.4\%) had residual disease after treatment. The most common failure was distant metastases. Five patients (21.7\%) had isolated
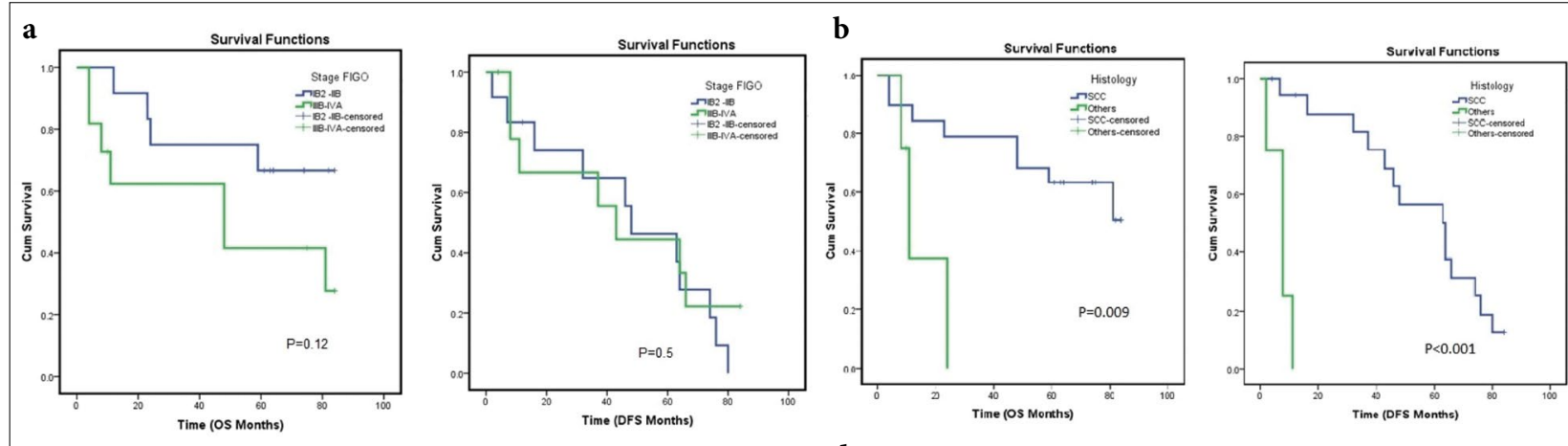

c
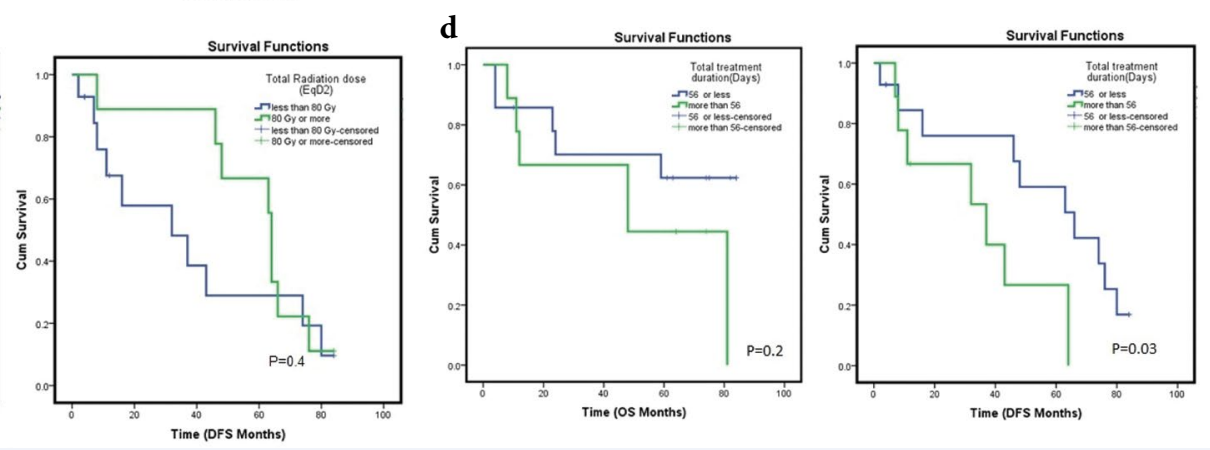

Fig. 2. Comparison of OS and DFS among (a) FIGO stages (b) Histology, SCC vs. Others (c) total radiation dose, $<80 \mathrm{~Gy}$ vs. $>80 \mathrm{~Gy}(\mathrm{~d})$ total treatment duration, $\leq 56$ days vs. $>56$ days. 
Table 3 Acute and chronic treatment-related toxicities

\begin{tabular}{|c|c|c|c|}
\hline & Acute (\%) & & Chronic (\%) \\
\hline Gastrointestinal (Diarrhoea) & & Gastrointestinal (Rectal bleeding) & \\
\hline NO & $10(43.5)$ & Grade 2 & $2(8.7)$ \\
\hline Grade I & $7(30.4)$ & & \\
\hline Gr ॥ & $4(17.4)$ & Lymphedema & \\
\hline Grade III & $2(8.7)$ & Grade 2 & $1(4.3)$ \\
\hline \multicolumn{4}{|l|}{ Dermatitis } \\
\hline Grade I & $12(52.2)$ & & \\
\hline Gr II & $10(43.5)$ & Vaginal stenosis & \\
\hline Grade III & $1(4.3)$ & No & $12(52.2)$ \\
\hline Genitourinary (Urinary frequency) & & Grade I & $7(30.4)$ \\
\hline Grade I & $5(21.7)$ & Grade II & $3(13)$ \\
\hline Grade II & $2(8.7)$ & Grade III & $1(4.3)$ \\
\hline \multicolumn{4}{|l|}{ Haematological } \\
\hline Grade I & $8(34.8)$ & Genitourinary (Cystitis) & \\
\hline Grade II & $4(17.4)$ & Grade 2 & $1(4.3)$ \\
\hline
\end{tabular}

Table 4 Comparison of failure with various parameters

\begin{tabular}{|c|c|c|c|c|c|}
\hline \multirow[t]{2}{*}{ Treatment relapse } & \multirow{2}{*}{$\begin{array}{c}\text { Total } \\
\text { patients (23) }\end{array}$} & \multirow{2}{*}{$\begin{array}{l}\text { Total dose (EqD2) } \\
\text { (Mean } \pm \text { SD) }\end{array}$} & \multirow{2}{*}{$\begin{array}{c}\text { Total treatment } \\
\text { duration (Mean } \pm \text { SD) }\end{array}$} & \multicolumn{2}{|c|}{ Stage } \\
\hline & & & & IB2-IIB (n=12), (\%) & IIIB-IVA (n=11), (\%) \\
\hline No & 12 & $79.88 \pm 6.55$ & $55.58 \pm 4.80$ & $8(34.8)$ & $4(17.4)$ \\
\hline Yes & 11 & $73.46 \pm 12.66$ & $56.55 \pm 7.2$ & $4(17.4)$ & $7(30.4)$ \\
\hline$P$ value & 0.1 & 0.7 & 0.1 & & \\
\hline \multicolumn{6}{|l|}{ Relapse/failure } \\
\hline No relapse & $12(52.2 \%)$ & & & & \\
\hline Relapse/failure & $11(47.8 \%)$ & & & & \\
\hline \multicolumn{6}{|l|}{ Type of failure/relapse } \\
\hline Loco regional (LR) & $2(8.7 \%)$ & & & & \\
\hline Distant Mets & $5(21.7 \%)$ & & & & \\
\hline LR+Distant Mets & $2(8.7 \%)$ & & & & \\
\hline LR+Abdominal (PAN) & $2(8.7 \%)$ & & & & \\
\hline \multicolumn{6}{|l|}{ Types of Distant failure } \\
\hline Lung & $4(17.4 \%)$ & & & & \\
\hline Bone & $3(13 \%)$ & & & & \\
\hline
\end{tabular}

PAN: Para-aortic node; SD: Standard deviation

distant metastases and two patients $(8.7 \%)$ had distant metastases with locoregional failure. Among the distant metastases, lung metastases were most common (4 patients, 17.4\%) followed by bone metastases ( 3 patients, $13 \%)$. Two patients (8.7\%) developed para-aortic lymph nodes during the follow-up.

The patients who had failure received a lower mean total radiation dose (EqD2) in comparison to those without any relapse (73.46 \pm 12.66 Vs $79.88 \pm 6.55$; $\mathrm{p}=0.1$ ). Patients with stage IIIB-IVA (7 patients, $30.4 \%$ ) experienced more failure than those with stage IB2-IIB disease (4 patients, 17.4\%); but the difference is not statistically significant $(\mathrm{p}=0.1)$.

\section{Discussion}

It is an inconclusive issue that whether the treatment outcomes of elderly patients with cervical cancer are poorer than their younger counterparts. Multiple retrospective series have shown mixed results in terms of treatment outcome and toxicity.[20-23]

In this study, we retrospectively reviewed the treatment outcome, toxicity, and patterns of failure of cervi- 
cal cancer patients of 75 years or older treated with definitive radiotherapy. The age of 75 years or older was selected based on the definition of "elderly" published in various cancer literature. [7,24-26]

The most relevant studies and guidelines recommend that the women with early-stage disease (FIGO stage IA-IB1/IIA1) are treated with surgery and those with locally advanced disease (FIGO stage IB2/ IIA2-IVA) with a combination of radiotherapy and chemotherapy. But older patients are less likely to receive all types of standard treatments compared with the younger ones. Possible reasons include concerns regarding co-existing medical co-morbidities, lack of access to care, increased toxicity, and physician or patient preference. Various literature have reported that elderly patients have treated less aggressively. [8,27-30]

Definitive radiotherapy is being considered as one of the primary treatment modality for elderly patients with cervical cancer. But compared to young patients, few elderly cervical cancer patients receive concurrent chemotherapy when treated with definitive radiotherapy.[31]

Despite the disparities in treatment, recent studies have demonstrated that elderly women tolerate pelvic radiotherapy and brachytherapy well. It was reported that elderly patients get equivalent survival to young patients when treated with definitive RT. A propensity-matched score analysis in Taiwan by Wang Y et al. showed no significant differences in cancer-specific survival, local and distant failure rates between the elderly group ( $\geq 75$ years), and young group ( $<60$ years), although OS was inferior in the elderly. The 5 -year OS in the elderly group was $49.2 \%$.[32]

Another retrospective analysis by Yoshida $\mathrm{K}$ et al. evaluated survival outcomes in 40 Japanese women of age 75 years or more reported 3-year overall and disease-specific survival of $58 \%$ and $80 \%$, respectively.[33] In the current study, the 5-year OS was $54.9 \%$ and DFS at 3 years and 5 years were $66.3 \%$ and $45.9 \%$ respectively.

Table 5 shows various published literature evaluating the treatment outcome of elderly

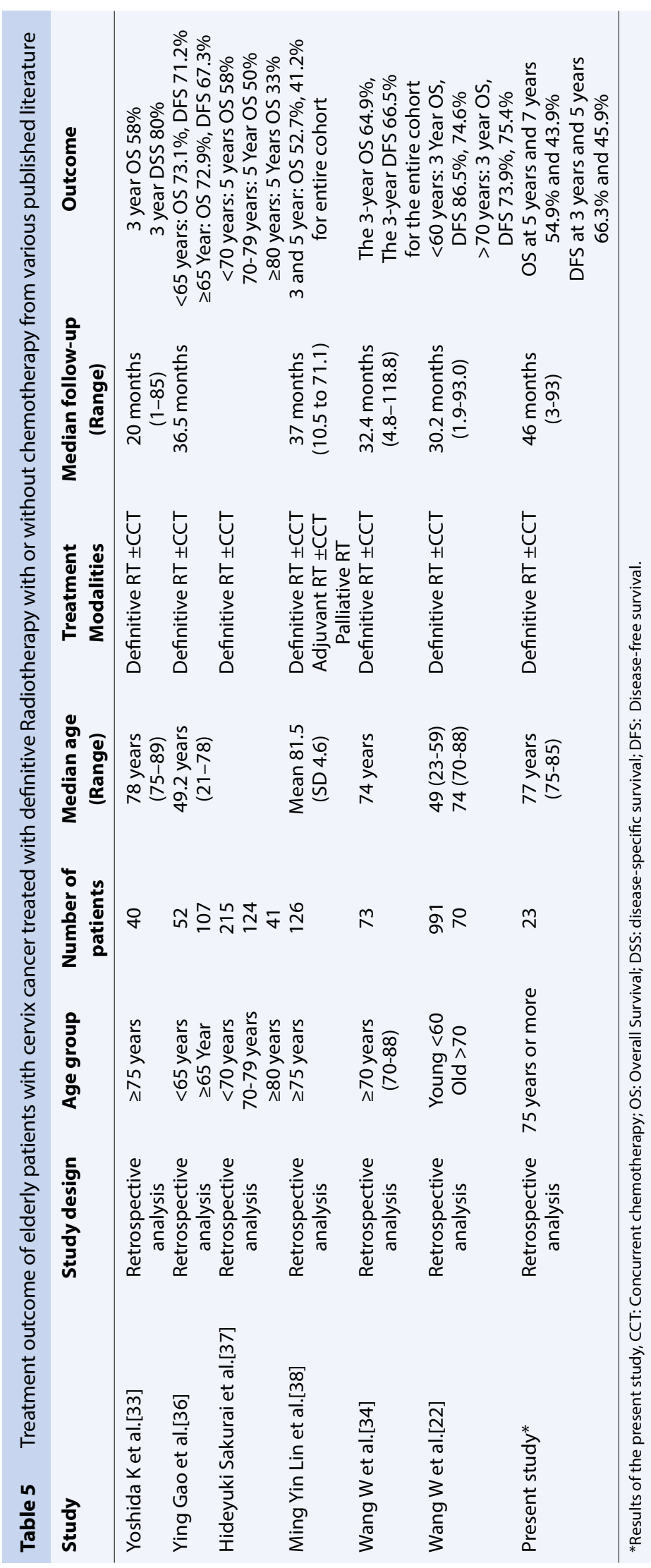


patients with cervical cancer treated with definitive radiotherapy with or without concurrent chemotherapy. The outcome of our study is also comparable to these published reports.

Similar to other reports, there was a preponderance of advanced-stage tumors in the present cohort at diagnosis. But the acute and late treatment-related toxicities are less frequent as compared to other published literature. It may be because only three patients received concurrent chemotherapy with inj Carboplatin in this study.

Wang $\mathrm{W}$ et al. retrospectively analyzed elderly cervical cancer patients ( $\geq 70$ years old) treated with definitive RT with or without concurrent chemotherapy. The 3-year OS of patients receiving RT and CCRT was 54.3\% and $83.1 \%$, DFS was $57.6 \%$ and $83.3 \%$ respectively. Out of 73 eligible patients; $15.1 \%$ had a locoregional failure, $12.3 \%$ experienced distant metastasis, and $5.5 \%$ had a locoregional failure and distant metastasis.[34] In our study, only three patients received concurrent chemotherapy with inj Carboplatin. The 5-year OS of the patients receiving CCRT was superior to those treated with radiotherapy alone but we got a contrasting result in DFS showing DFS of the CCRT group is inferior to only RT group. This conflict of the result may be due to the low sample size and the fact that only three patients received concurrent chemotherapy. In the present study, distant metastatic failure was higher (21.7\%). The lung was the most common site of distant metastasis (17.4\%). Patients with stage IIIB-IVA experienced more relapse than those of stage IB-IIB.

The national comprehensive cancer network (NCCN) recommends that the entire treatment time for cervical cancer should be less than 8 weeks.[35] The median treatment duration for the entire cohort of this study was 55 days (42-70 days). The patients completing treatment within 8 weeks have a superior OS and DFS.

\section{Limitations}

The current study has many limitations. Firstly, it is a retrospective study and the study population is heterogeneous. Further, the sample size was small and the EBRT in our patients was delivered with a conventional technique. None of the patients received Cisplatin-based concurrent chemotherapy. Therefore, further research in elderly patients with cervical cancer in a prospective design with a larger sample size needs to be done.

\section{Conclusion}

The number of elderly patients with cervical cancer is increasing and definitive radiotherapy gives good treatment outcomes with acceptable toxicity. However, caution should be taken when more aggressive treatment modalities like CCRT are used. In our study, good survival outcome with acceptable early and late treatmentrelated toxicity was observed. It can be concluded that definitive radiotherapy is well tolerated by elderly patients and should be considered whenever feasible.

Peer-review: Externally peer-reviewed.

Conflict of Interest: On behalf of all authors, the corresponding author states that there is no conflict of interest.

Ethics Committee Approval: The study was approved by Institutional Ethics Commitee; BBCI Medical Ethics Committee (Registration No: ECR/1040/Inst/AS/2018), vide approval letter Ref No. BBCI-TMC/Misc-01/MEC/71/2019 Date $27^{\text {th }}$ July 2019.

Financial Support: This research did not receive any specific grant from funding agencies in the public, commercial, or not-for-profit sectors.

Authorship contributions: Concept - G.S.; Design - G.S., J.N.; Supervision - A.K.K.; Funding - None; Materials L.B., J.N.; Data collection and/or processing - L.B., J.N.; Data analysis and/or interpretation - J.N., G.S.; Literature search P.P.M., G.S., J.N.; Writing - J.N., G.S.; Critical review - M.B.

\section{References}

1. WHO. Available at: https://www.who.int/. Accessed Aug 4, 2020.

2. Global Cancer Observatory. Available at: https://gco. iarc.fr/. Accesed Aug 4, 2020.

3. Arbyn M, Weiderpass E, Bruni L, de Sanjosé S, Saraiya M, Ferlay J, et al. Estimates of incidence and mortality of cervical cancer in 2018: a worldwide analysis. The Lancet Global Health 2020;8(2):e191-e203.

4. Canfell K, Kim J, Brisson M, Keane A, Simms K, Caruana $\mathrm{M}$, et al. Mortality impact of achieving WHO cervical cancer elimination targets: a comparative modelling analysis in 78 low-income and lower-middle-income countries. The Lancet 2020;395(10224):591-603.

5. Yanazume Y, Yanazume S, Iio K, Yonekura R, Kojima N, Uchida N, et al. Major causes of impractical brachytherapy in elderly patients with uterine cervical cancer. J Obstet Gynaecology Res 2014;40:1725Y1732.

6. Indian Council of Medical Research. National Cancer Registry Programme. Consolidated Report of Hospital Based Cancer Registries 2001-2003. Avail- 
able at: https://www.ncdirindia.org/All_Reports/ HBCR_2001_03/HBCR_2001_03.pdf. Accessed Aug 4, 2020.

7. Sharma C, Deutsch I, Horowitz D, Hershman D, Lewin S, Lu Y, et al. Patterns of care and treatment outcomes for elderly women with cervical cancer. Cancer 2011;118(14):3618-26.

8. Nogueira-Rodrigues A, de Melo A, Garces A, Paulino E, Alves F, Vilaça M, et al. Patterns of Care and Outcome of Elderly Women Diagnosed With Cervical Cancer in the Developing World. International Journal of Gynecological Cancer 2016;26(7):1246-51.

9. Stanhope CR, Smith JP, Wharton JT, Rutledge FN, Fletcher GH, Gallager HS. Carcinoma of the cervix: The effect of age on survival. Gynecol Oncol 1980;10:188-93.

10. Delaloye JF, Pampallona S, Coucke PA, De-Grandi P. Younger age as a bad prognostic factor in patients with carcinoma of the cervix. Eur J Obstet Gynecol Reprod Biol 1996;64:201-5.

11. Lybeert ML, Meerwaldt JH, van-Putten WL. Age as a prognostic factor in carcinoma of the cervix. Radiother Oncol 1987;9:147-51.

12. Benstead K, Cowie VJ, Blair V, Hunter RD. Stage III carcinoma of cervix. The importance of increasing age and extent of parametrial infiltration. Radiother Oncol 1986;5:271-6.

13. Spanos WJ Jr, King A, Keeney E, Wagner R, Slater JM. Age as a prognostic factor in carcinoma of the cervix. Gynecol Oncol 1989;35(1):66-8.

14. Huang HJ, Chang TC, Hong JH, Tseng CJ, Chou HH, Huang KG, et al. Prognostic value of age and histologic type in neoadjuvant chemotherapy plus radical surgery for bulky $(>/=4 \mathrm{~cm})$ stage IB and IIA cervical carcinoma. Int J Gynecol Cancer 2003;13(2):204-11.

15. Chen RJ, Lin YH, Chen CA, Huang SC, Chow SN, Hsieh CY. Influence of histologic type and age on survival rates for invasive cervical carcinoma in Taiwan. Gynecol Oncol 1999;73(2):184-90.

16. Junor EJ, Symonds RP, Watson ER, Lamont DW. Survival of younger cervical carcinoma patients treated by radical radiotherapy in the west of Scotland 19641984. Br J Obstet Gynaecol 1989;96(5):522-8.

17. Van der Graaf Y, Peer PG, Zielhuis GA, Vooijs PG. Cervical cancer survival in Nijmegen region, the Netherlands, 1970-1985. Gynecol Oncol 1988;30(1):51-6.

18. Pecorelli S. Revised FIGO staging for carcinoma of the vulva, cervix, and endometrium. International Journal of Gynecology \& Obstetrics 2009;105(2):103-4.

19. International Commission on Radiation Units and Measurements (1985) Dose and volume specification for intracavity therapy in gynecology. ICRU report 38. ICRU, Washington. Available at: https://icru. org/home/reports/dose-and-volume-specification-for-reporting-i- ntracavitary-therapy-in-gynecology-report-38. Accessed Nov 26, 2020.

20. Wright J, Gibb R, Geevarghese S, Powell M, Herzog $\mathrm{T}$, Mutch $\mathrm{D}$ et al. Cervical carcinoma in the elderly. Cancer. 2004;103(1):85-91.

21. Chakraborty S. How well do elderly patients with cervical cancer tolerate definitive radiochemotherapy using RapidArc? Results from an institutional audit comparing elderly versus younger patients. Ecancermedicalscience 2014;8:484.

22. Wang W, Liu X, Meng Q, Zhang F, Hu K. Comparisons of survivals and toxicities between young and elderly patients with cervical cancer treated with definitive radiotherapy or concurrent chemoradiotherapy. Taiwanese Journal of Obstetrics and Gynecology 2019;58(3):364-9.

23. Gao Y, Ma J, Gao F, Song L. The evaluation of older patients with cervical cancer. Clinical Interventions in Aging 2013;8:783-8.

24. George EM, Tergas AI, Ananth CV, Burke WM, Lewin $\mathrm{SN}$, Prendergast E, et al. Safety and tolerance of radical hysterectomy for cervical cancer in the elderly. Gynecol Oncol 2014;134:36-41.

25. Kumthekar PU, Macrie BD, Singh SK, Kaur G, Chandler JP, Sejpal SV. A review of management strategies of malignant gliomas in the elderly population. Am J Cancer Res 2014;4:436-44.

26. Breccia M, Latagliata R, Stagno F, Luciano L, Gozzini A, Castagnetti F, et al. Charlson comorbidity index and adult comorbidity evaluation-27 scores might predict treatment compliance and development of pleural effusions in elderly patients with chronic myeloid leukemia treated with second-line dasatinib. Haematologica 2011;96:1457-61.

27. Diver EJ, Hinchcliff EM, Gockley AA, Melamed A, Contrino L, Feldman S, et al. Assessment of treatment factors and clinical outcomes in cervical cancer in older women compared to women under 65 years old. J Geriatr Oncol 2018;9(5):516-9.

28. Pfaendler KS, Chang J, Ziogas A, Bristow RE, Penner KR. Disparities in Adherence to National Comprehensive Cancer Network Treatment Guidelines and Survival for Stage IB-IIA Cervical Cancer in California. Obstet Gynecol 2018;131(5):899-908.

29. Roque DR, Cronin B, Robison K, Lopes V, Rizack T, Dizon DS. The effects of age on treatment and outcomes in women with stages IB1-IIB cervical cancer. J Geriatr Oncol 2013;4(4):374-81.

30. Morris M, Eifel PJ, Lu J, Grigsby PW, Levenback C, Stevens RE, et al. Pelvic radiation with concurrent chemotherapy compared with pelvic and para-aortic radiation for high-risk cervical cancer. $\mathrm{N}$ Engl J Med 1999;340(15):1137-43.

31. Goodheart M, Jacobson G, Smith BJ, Zhou L. Che- 
moradiation for invasive cervical cancer in elderly patients: outcomes and morbidity. Int J Gynecol Cancer 2008;18(1):95-103.

32. Wang Y, Wang C, Fang F, Chen H, Hsu H, Huang Y, et al. Differences in the outcomes and complications between elderly and younger uterine cervical cancer patients treated by definitive radiotherapy - A propensity score-matched study. Gynecologic Oncology 2017;145(2):277-83.

33. Yoshida K, Sasaki R, Nishimura H, Miyawaki D, Kawabe T, Okamoto Y, et al. Radiotherapy for Japanese elderly patients with cervical cancer: preliminary survival outcomes and evaluation of treatment-related toxicity. Archives of Gynecology and Obstetrics 2010;284(4):1007-14.

34. Wang W, Hou X, Yan J, Shen J, Lian X, Sun S, et al. Outcome and toxicity of radical radiotherapy or concurrent Chemoradiotherapy for elderly cervical cancer women. BMC Cancer 2017;17(1):510.

35. NCCN Clinical Practice Guidelines in Oncology. Available at: https://www.nccn.org/professionals/ physician_gls/default.aspx\#site. Accessed Aug 12, 2020.

36. Gao Y, Ma J, Gao F, Song L. The evaluation of older patients with cervical cancer. Clinical Interventions in Aging 2013;8:783-8.

37. Sakurai H, Mitsuhashi N, Takahashi M, Yamakawa M, Akimoto T, Hayakawa K, et al. Radiation Therapy for Elderly Patient with Squamous Cell Carcinoma of the Uterine Cervix. Gynecologic Oncology 2000;77(1):116-20.

38. Lin M, Kondalsamy-Chennakesavan S, Bernshaw D, Khaw P, Narayan K. Carcinoma of the cervix in elderly patients treated with radiotherapy: patterns of care and treatment outcomes. Journal of Gynecologic Oncology. 2016;27(6). 